在这一事例中, 若 $A_{1}$ 是反稹子, $B_{2}$ 㳬 $\alpha$ 粒子, 則 它們在乳胶中的平均自由程应該分別为 $\lambda_{\overline{\mathrm{p}}}=17.2 \pm$ 1.77 匡米 ${ }^{[7]}$ 及 $\lambda_{\alpha}=19.9$ 厘米 ${ }^{[8]}$ 。实际覌察到碰撞間 的距离 $x_{\bar{p}}=0.0639$ 厘 米, 而 $x_{a}=0.0288$ 厘 米。若 棓人为二碰撞在 $\boldsymbol{x}$ 距离产生的几率为

則可求出 $P_{x \bar{p}}$ 改 $P_{x a}$ 。

$$
p_{x}=1-e^{-x / \lambda},
$$

同时因为乳胶片的厚度是有限的，我們还需考虑 长度为 $x$ 的径跡能够存在于厚度 $t$ 的乳胶片中的几來 $P_{g \circ}$ 当忽略了边緣效应时,其表示式为

$$
\begin{array}{cc}
P_{g}=\left[1-\frac{(x+2 k)}{2 t}\right] ; & x+2 k<t \\
P_{g}=t / 2(x+2 k) ; & x+2 k>t
\end{array}
$$

$k$ 为辨䚯 $x$ 两端星跡所管附加的常数, 我們取作 $50 \mu$ 。根据上迌关柔可以得到这一級联事例产生的总 几率 $P$ 为

$$
P=P_{x \bar{p}} P_{x \alpha} P_{g \bar{p}} P_{g^{\alpha}}=1.5 \times 10^{-6} 。
$$

率。

$P_{g \bar{p}}$. 及 $P_{g a}$ 代表 $\bar{p}$ 及 $\boldsymbol{\alpha}$ 径跡的上述几侧关系的几

討論:

在这一事例中考虑了反粒子的作用，但得到的总 几率仍然很小。同时这是一个能量較低的事例。核的 相互作用截面肯定不会有很大的变化。因此我們只能 把它的出現作为偶然的机遇来看待。我們也可以看出 若把 H. Yagoda 等所覌察的事例作为是反物稹引起的 話，持不会将其出現的几率增加很多 ${ }^{[3]}$; 而高能粓子 就盾子而言，目前根据能量到 $9 \mathrm{Bev}$. 为止的可靠数据 看来，其在乳胶中的平均自由程也末出現隇少的現貌 $\left(E_{p} \sim 9\right.$ Bev. $\lambda=3.4 .7 \pm 1.5$ 厘米 $\left.{ }^{[9]}\right)$ 。同时我們䚯为 若把这些事例都作为一种偶然的机遇来看，也抹非完 全不能理解，因为所覌察到的 A 星的总数及其全部分 枝数都是很大的。

作者使用了科学院原子能研究所供給的核乳胶 片; 扭承王普先生及何瓄、楊錫昣、刘㭉賢等同志指 导与协助，特此志謝。

\section{張聞迪于 良}

(山东大学)

[1] Yagoda, H.: Nuovo Cim., 6, 559 (1957).

[2] Milone, A.: Suppl. Nuovo Cim., 2, 353 (1954).

[ 3 ] 德永等: Nuovo Cim., 5, 517 (1957).

.[4] Shapiro, M.: Proc. of the 6th Annual Rochester Conference, 9, 26 (1956).

D [ 5 ] 于良:山东大学学报, 1959 年第一期, 129 頁。

[ 6 ] Barkas, W. H, et al.: Phys. Rev., 105, 1037 (1957).

[7] Ekspong, G.: Proc. of the 7th. Annual Rochester
Conference, 10, 18 (1957).

[8] Ilford Research Laboratory, Circuląr of August, 10, 1956.

-[9] Богачев, Н. П. и пр.: Атомная энергия, 4, 281 (1958).

\section{延胡索素乙藥理作用的 进一步研究}

延胡索素乙 (簡称乙素) 是中䓎延胡索 (Corydalis a mbigua ) 有效成分之一，有关的化学工作在 1928-

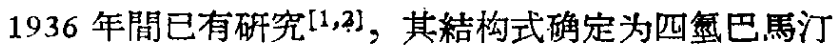
(dl-Tetrahydropalmatine)（I）。乙素的药理作用虽然有 人研究过，但是它的鏑痛作用为我們首先发現，其鎮 痛指数比延胡索素甲、丑为高 ${ }^{[3]}$ ，玤且不容易产生耐

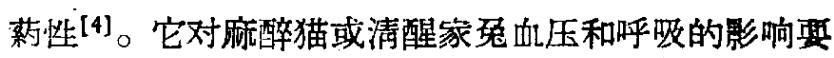

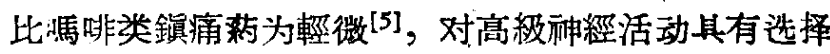
性的抑制作用 ${ }^{[6]}$ 。这些資料都說明乙素是一个有价值 的中枢抑制剂。为了便于过渡临床試用，故进行有关 的毒性研究，找进一步对乙素的中枢神經系統的䓎理 作用作了較全面的分析。

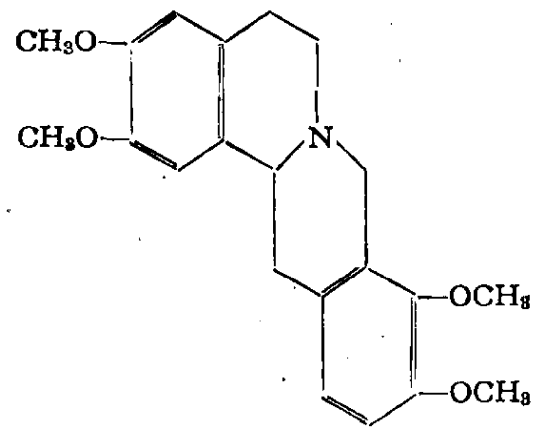

\section{一、毒性試銐}

猴子 4 只单次口服乙素硫酸盐 85 - 110 毫克/公 斤，对外界刺激反应減弱，抹閉眼欲睡，但触动它們 时仍能惊醒，这种鎮静表現維持 2-4 小时之久; 此 外，末覌察到其他不良副作用。另有 2 只䒨子剂量为 180 毫克/公厅，除了有鎮靜作用外，还出現輕微的呕 吐、肌肉紧张、四肢震副、心率減少、血压波动等現 象, 但心电图和呼吸均为正常。这些不良的副作用可 在 2- 3 天內恢复。另有猴子 2 只每天口服乙素硫酸 盐 85 毫克/公厅, 每天 1 次, 共 2 周。在給䓎期前几 天中动物有鏔静表現, 約在 1 周左右才出現上述一些 不良副作用，10天左右在小便中出現管型。到期解剖 1 只猴子，未覌察到朋显的外表变化，柾切片检查， 在心脏、督脏有輕微混浊肿胀。末解剖猴子 1 只, 在 停䓶 1-2 周內可恢复正常。还有猴子 2 只皮下注射 乙素硫酸盐 80 毫克/公斤，数分鈡后就出現极度安静 
和瞌睡現像，触动它則被惊醒，䄪历 1.5 小时睡意可 消失，而动物仍然安靜，4-5 小时可恢复，对呼吸 心电图未有明显影响。

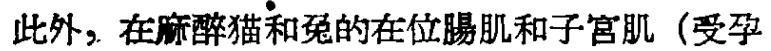
和未受孕）进行試驗，从皮下注射乙素 40 毫克/公斤 无明显的影响，故推論乙素对平滑肌不会产生不良的 副作用。

监佅根据我們的建議，一般病例每人服用乙 秦 75-150 毫克，該剂量䄪为猴子毒性 剂量的 1/25-

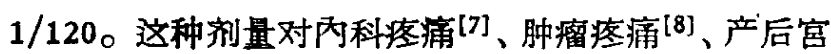
縮痛 ${ }^{[9]}$ 均有良好效能，外伤性銳痛效果較差 ${ }^{[7,10]}$ 。乙 素对神經性疼痛的緩解也有效 ${ }^{[11]}$ 。在临床世覌察到 嗜睡和釦静作用。

在监休还进行了对产妇产程影响的初步覌察, 融 为乙和有催产作用, 其优点是安全度大,不影响胎儿， 世不影响产妇，而且乙絜具有一定錎痛和鎮静效能， 能減輕产妇的痛苦。这項工作正在継續研究中。

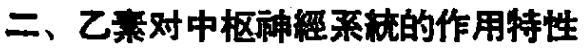

（1）乙素的鏜靜作用及机制分析:

腹腔注射乙素 20-40 毫克/公斤，能延长环己烯 巴比努对小白鼠的睡眠时間, 又能減少小白鼠在滚筒、 轉柾試驗时的活动。在光电管試驗时，乙素能減少小 白鼠的自发活动和对抗小剂量苯丙胺可起的兴奋。这 些試驗均說明乙素有明显的錤静作用。

給猫皮下注射乙素10-20毫克/公厅，对它的防御 性条件反射无明显的影响。剂量增大为 30 毫克/公斤， 在給莐 20-30 分鈡; 动物出現兴奋和不安現象,有怒 叫、排便、呕吐等表現。而后安静,此后条件反射和非条 件反射也有部分消失，該作用可持綂 2-3 小时之久。

給猫側脑室注射乙素 1-2 毫克/公斤，可使动物 的恐惧、造避行为消失; 抹出現睦睡現像，易为外界 刺激所惊醒，而后又入洪。这作用可持緗 2 小时。

清醒家免的脑皮稹电波主要为低电压快波，当静 脉注射乙素 15-20 毫克/公斤后 3-7 分鈡，脑皮 层 电波䡒变为高电压慢波，这时对外界刺激引起脑电波 的惊醒反应能明显減弱，历 $20-40$ 分鈡可获得恢复。

（2）乙素的抗嘬吐和抗惊㷧作用:

狗皮下注射乙妻 40 㲠克/公斤，有明显的鎮靜作 用，抹能对抗小剂量夫水嗎啡（0.1一0.2 毫克/公斤） 的催吐作用，但在大剂量去水嗎啡 (1 毫克/公斤) 时 其作用不明显。乙素不能对扮硫酸銅的致吐作用，所 以乙素銫吐作用很可能是中枢性的。

給小里鼠腹腔注射乙素 90 毫克/公厅，可使士的

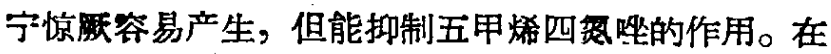

电休克的試驗中乙素无保护作用。

\section{三、小結}

从上述資料看来，乙絭的毒性很小，临休上使用 安全度很高，不但对內科疾病有良好䤾痛效能，抹且 具有催产作用，故是一个有希望的新药。从药理資料 看来，乙素不仅是一个鐭痛䄪，而且很可能是具有特 殊鎭靜作用的获物，值得进一步研究。

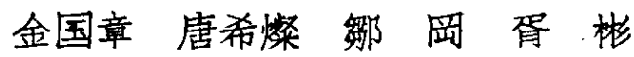 (中国科学院萂物研究所)}

[1] Chou, T. Q. (赵承硍): Chinese J. Physiol., 1928, 2: $203-218 ; 1929,3: 69-74$.

[ 2 ] Huang, M. L. (濒鳴龙): Berichte, 1936, 69: 1737 -1745 .

[ 3] 金国章、甭彬,生理学报, 1957,21: 150-157。

[4]㔻彬、金国章,生理学报, 1957,21: 158-162。

[5] 金国章、陈瑞娧、王道苑、㔻彬,䒬学学报, 1958,6:2630 。

[6] 甭彬、徐光稳,生理学报, 1958,22:40-46。

[7]中山医院:待发表,1959。

[ 8 ] 第二軍医大学附属医院, 1959,求发表資料。

[ [9] 上海第一医学院妇产科医院, 1959, 未发表資料。

[10] 第二軍医大学外伤医院, 1959,末发表貸料。

[11] 上海第一医学院第一附属医院朔經科, 1959,末发表資 料。”

\section{自动控制条件反射仪}

研究治疗精神病䓶物对人类和动物的高級神經活 动影响，对明这些䔙物的作用规律和机制有极大的 意义。中国科学院药物呼究所神經䓎理实驗室原来进 行此項試驗时, 采用一般的經典式条件反射方法, 此 方法既須經常覌察，且所得資料又不准确。因而如能 建立一套完整的自动化操作和自动記录装硻, 非但节 省了很多人力, 而且得到的資料也較为客观可莽。

在党的总路鼓舞下, 药物研究所电子室和金工 場的同志在实驗室同志筑切配合下，用了两个多月时 間，制成了自动控制条件反射仪，經試用，基本符合要 求。仪器构造共分 6 个部分：1. 店定比例部分, 2 .固 定間隔部分，3.不定間隔部分，4.条件性迴避反射部 分, 5 .造择性低頻强化部分, 6 .换轉部分。

利用这部仪器, 能进行 5 种不同类型的条件 反 射，㨢自动地由一种条件反射轉換为号一种，在完 全没有人的参于下可以工作四个牛小时，因此大大地 节省时間，提高效率，所得結果也更客覌。只要改变 放置动物的实驗箱，还能适用于各种动物的条件 反 射，如猴子、大白鼠、鸽子等。

\section{中国科学院藥物呼究所}

